\title{
Erratum to: Trace Element Levels in Congenital Hypogonadotrophic Hypogonadism
}

\author{
A. Aydogdu ${ }^{1}$ - C. Haymana ${ }^{1}$ - B. Soykut ${ }^{2}$ - O. Erdem $^{2} \cdot$ Y. Basaran $^{1} \cdot$ K. Baskoy ${ }^{3}$.

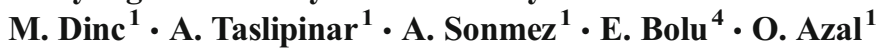

Published online: 22 October 2015

(C) Springer Science+Business Media New York 2015

\section{Erratum to: Biol Trace Elem Res (2015)}

DOI 10.1007/s12011-015-0496-Z

In the above-mentioned article, the author name A. Aydogdu was written incorrectly as A. Aydogan. However, this error has been already corrected in both the referenced article and in the author listing for this article. The authors regret the oversight.

The online version of the original article can be found at http://dx.doi.org/ 10.1007/s12011-015-0496-z.

\footnotetext{
C. Haymana

cemhaymana@hotmail.com
}

1 Department of Endocrinology and Metabolism, Gulhane School of Medicine, 06018 Etlik, Ankara, Turkey

2 Department of Pharmaceutical Toxicology, Gulhane School of Medicine, 06018 Etlik, Ankara, Turkey

3 Department of Endocrinology and Metabolism, Haydarpasa Training Hospital, 34668 Istanbul, Turkey

4 Department of Endocrinology and Metabolism, Memorial Atasehir Hospital, 34750 Atasehir, Istanbul, Turkey 